\title{
Política econômica, mercado de trabalho e democracia: o segundo governo Dilma Rousseff
}

\author{
LIANA MARIA DA FROTA CARLEIAL ${ }^{I}$
}

\section{Introdução}

$\mathrm{E}$

M 15 de setembro de 2014, o ministro da Fazenda, naquela ocasião Guido Mantega, fez uma apresentação no Fórum de Economia da Fundação Getulio Vargas, na qual desenvolveu um balanço da economia brasileira e das medidas implementadas pelo governo Dilma Rousseff para enfrentar os efeitos da crise econômica e seus desdobramentos no Brasil. Há ali uma avaliação critica da política econômica e o reconhecimento de um necessário ajuste macroeconômico para que se recuperassem as condições de um novo ciclo de crescimento. A proposta apresentada era um ajuste gradual contraposto a um ajuste de choque que impusesse uma forte redução dos gastos públicos e do crescimento econômico, aumento do desemprego, redução do salário real, desmonte da política de valorização do salário mínimo, encolhimento do investimento público e aprofundamentos da financeirização e da desindustrialização brasileiras. Esse segundo ajuste o ex-ministro intitulou de neoliberal. Mas, de forma surpreendente é esse o ajuste que o segundo governo Dilma está implementando.

É surpreendente, porque a candidata Dilma apresentou, durante a campanha eleitoral, um programa compromissado com os interesses dos trabalhadores, prometendo manter o emprego e a renda. Esse ajuste que, ironicamente, promete o crescimento econômico acaba eliminando as chances reais de crescimento num futuro próximo por reduzir o investimento, o emprego, a renda, a arrecadação de impostos e comprometer a engenharia dos gastos sociais construída nos últimos anos. Ademais, a escolha pela permanência da política em curso até 2014 parecia ter sido validada pelas urnas, quando a presidenta Dilma foi reeleita com $54,5 \%$ dos votos válidos no país.

O estopim para a decisão de implementar o ajuste neoliberal parece ter sido a confirmação de um déficit de $0,6 \%$ do PIB brasileiro, em 2014, após 17 anos de superávits consecutivos. Como não é possível separar economia da política, atribuímos algum peso também à reação de inconformismo do grupo derrotado que passou a ameaçar a presidenta reeleita com um possível impedi- 
mento. Assim, a adoção do ajuste neoliberal parece ter sido também uma tentativa de ser "aceita" pelo grupo político derrotado e seus eleitores frustrados.

O principal objetivo deste artigo é destacar as tendências do mercado de trabalho brasileiro submetido às consequências do ajuste fiscal implementado pelo segundo governo Dilma. Mesmo tratando-se de uma análise conjuntural do mercado de trabalho, no atual quadro econômico-político brasileiro, as questões estruturais obrigatoriamente estão presentes enquanto restrições ao momento presente e condicionantes das possibilidades futuras.

A reflexão sobre o mercado de trabalho em qualquer momento histórico exige sempre que consideremos o que é, exatamente, o mercado de trabalho. Sob o modo de produção capitalista, o mercado de trabalho é uma esfera subordinada ao nível e ao ritmo da atividade econômica. Logo, a posição do país na divisão internacional do trabalho, seu perfil tecnológico e industrial, bem como sua capacidade de implementar políticas econômicas favoráveis à geração de empregos e sua capacidade de regular tal mercado são elementos importantes.

Este artigo está estruturado em quatro sessões além das considerações finais e desta introdução. A primeira aborda os condicionantes histórico estruturais da formação do nosso mercado de trabalho, com destaque para o perfil da nossa estrutura produtiva; as três seguintes abordam os temas indicados no título do artigo: a política econômica, o mercado de trabalho e a democracia. Finalmente, traçamos as nossas observações finais.

\section{Condicionantes histórico-estruturais}

O Brasil, tal como a América Latina, guarda uma especificidade histórica que é sua inserção no mercado internacional na condição de economia exportadora de produtos primários que lhe conferiu a condição de periferia do capitalismo. Essa condição expressa uma dependência de recursos externos e de tecnologia, a constituição de uma estrutura produtiva heterogênea, pouco diversificada com implicações desastrosas sobre a constituição do seu mercado interno, instalando assim uma tendência de concentração de renda e, ainda, um mercado de trabalho heterogêneo e limitado (Carleial, Ferreira; 2013).

A presença de uma estrutura produtiva pouco diversificada, apontada pelos mais importantes desenvolvimentistas latino-americanos ${ }^{1}$ denuncia a limitada capacidade de geração de postos de trabalho, especialmente de melhor qualidade e melhores salários. A entrada tardia do Brasil na divisão internacional é um "espantalho" presente na nossa história, ou seja, é um condicionante histórico-estrutural.

Durante o século XX o Brasil construiu uma base industrial que internalizou o setor que produz máquinas com máquinas, porém não conseguiu reverter a sua vulnerabilidade externa. Mesmo reconhecida como um obstáculo ao desenvolvimento de longo prazo, esse objetivo é sempre subordinado às urgências, ou seja, à macroeconomia de curto prazo. Assim, as últimas três décadas nos fizeram ainda mais prisioneiros das tendências mundiais (Carleial, 2004). 
Arend e Fonseca (2012), a partir de um desenvolvimento de cunho neoschumpeteriano, especialmente centrado na análise de ondas longas desenvolvido por Perez (2004), evidenciam que no período 1955-1980 o Brasil conseguiu realizar seu catching up centrado numa estratégia de crescimento alicerçado em recursos externos. No entanto, a partir da crise dos anos 1980, quando a nova revolução tecnológica centrada na microeletrônica se instalou, ficou evidente a fragilidade da estratégia de delegar ao capital estrangeiro os setores mais dinâmicos da indústria brasileira. Para esses autores, nos últimos 25 anos, o país ingressou num processo de falling behind o que colocou o país numa trajetória de atraso relativo no cenário mundial.

Ademais, a partir nos anos 1990 ocorreram significativas mudanças na economia global tanto do lado produtivo como do lado financeiro. Intensifica-se a financeirização nessa fase do capitalismo, quando a riqueza financeira cresce mais rapidamente do que a riqueza real, em decorrência da abertura dos mercados financeiros, impulsionando um forte movimento de concentração de riquezas. Multiplicaram-se os aplicativos financeiros que atravessam rapidamente as fronteiras geográficas, sem quaisquer regras ou controles, produzindo crises periódicas, como foi a de 2008, cujos efeitos ainda não se esgotaram (Chesnais, 2004; Piketty, 2014).

Do lado produtivo também muitas mudança ocorreram, desde o processo de relocalização industrial no nível mundial, a emergência de novos formatos organizacionais, tais como firmas-rede, as redes de firmas, o processo de subcontratação em diferentes níveis geográficos. Esse processo gerou mudanças nos padrões da concorrência intercapitalista, acirrando a competição, o ritmo das fusões e aquisições e a desnacionalização das estruturas produtivas de países que não estão no centro desses movimentos. Essas mudanças acentuam o caráter oligopólico das estruturas produtivas contemporâneas, com forte poder de marcação de preços, e permanentemente incitadas a se guiar pelos patamares dos rendimentos vigentes nos mercados financeiros.

Esse quadro geral fragiliza muito os mercados de trabalho uma vez que os trabalhadores ao longo desse período perderam base sindical, assistiram a um intenso movimento do capital em busca de salários mais baixos e a fragmentação da sua composição em razão da atuação das redes de firmas e da subcontratação generalizada.

\section{A política econômica do período 2003-2015}

Desde a discussão desenvolvida no clássico Economics, de Samuelson e Nordhahus (2005), há uma supremacia dos objetivos da macroeconomia na definição da política econômica. Nesse caso, os objetivos seriam: o crescimento da produção nacional, a manutenção de taxas elevadas de emprego e a estabilidade dos preços. Assim, os instrumentos mais importantes seriam a política fiscal e a política monetária. Kaldor vai ampliar esses objetivos, incluindo o equilíbrio externo. No entanto, o marco exigido para a política econômica atualmente vai 
muito além desses objetivos; em primeiro lugar, porque as sociedades capitalistas contemporâneas são bem mais complexas e, em segundo lugar, porque o conflito capitalismo versus democracia, que é permanente, cobra cada vez dos governos a incorporação dos anseios das populações envolvidas. Nos modelos clássicos de desenvolvimento a questão democrática nem chega a ser incorporada.

$\mathrm{Na}$ contemporaneidade o que se espera da política econômica é que ela reflita os compromissos assumidos pelos governos que, em cada momento, assumem a responsabilidade de condução do Estado. Logo, ela resulta de um processo conflituoso e de enfrentamentos entre grupos de interesses, o que exige que a política econômica seja capaz de evidenciar que "tem um lado", ou seja, que fez opções. Assim, espera-se que a política econômica esteja no campo da economia política e que reflita a crítica do seu tempo, do seu momento histórico.

O período 2003-2015 não é um período homogêneo, mas está aqui agrupado para identificar os governos do PT, ou como diz Cerqueira Leite (2015): os governos que "trouxeram a plebe para o poder".

A primeira fase da era Lula-Dilma, 2004-2011, promoveu uma taxa média anual de crescimento real do PIB de $4,3 \%$, segundo o IBGE.

A política macroeconômica do governo Lula manteve, inicialmente, as linhas gerais do governo que o antecedeu. Na realidade, ele recebeu o país já submetido ao processo que chamei de subdesenvolvimento globalizado (Carleial, 2004); esse processo indica que as escolhas de política econômica da década de 1990 viabilizaram a entrada passiva do país na globalização através da abertura comercial, da flexibilização dos mercados, das privatizações e da reestruturação produtiva, processos esses que desnacionalizaram elos importantes das cadeias produtivas. O projeto neoliberal implantado tinha as seguintes características: a) controle da inflação; b) abertura comercial com o objetivo de ampliação da competitividade e privatização das grandes empresas governamentais; c) desregulamentação financeira e dos mercados de trabalho; e d) controle dos gastos públicos, com a redução do papel do Estado. A utilização da âncora cambial instituída no âmbito do Plano Real, que sobrevalorizou a moeda nacional, permitiu um forte movimento expansionista das importações, centrado em bens de capital e intermediários, cujos resultados foram a ampliação dos componentes importados na produção nacional e, ainda, a racionalização dos processos produtivos, ambos com efeitos danosos sobre o emprego.

A atuação do governo Lula que, mesmo ancorado numa política macroeconômica que preservou o superávit primário, pagou juros altos e manteve a estrutura tributária regressiva conseguiu produzir mudanças significativas.

No segundo governo Lula, o quadro altera-se favoralmente, apesar dos efeitos da repercussão do chamado "mensalão"; foi produzida uma conjugação entre um ambiente externo favorável com grande liquidez internacional, baixas taxas de juros e uma melhoria significativa nos termos de troca, favorecendo o 
Brasil. O crescimento da China engendra uma relação na qual o Brasil exporta grãos e minérios e importa produtos manufaturados. Aqui ocorre um fenômeno recorrente na nossa história econômica: quando os termos de troca nos favorecem, o caráter de economia primário exportadora se revitaliza e as mudanças estruturais são adiadas.

Na realidade, desde 2003, como consta do Plano Plurianual (PPA) 20042007, havia a intenção de instalar no país um modelo de produção e consumo de massas que valorizasse o extenso mercado interno brasileiro. Os meios para isso foram estimular a formalização do mercado de trabalho, reduzindo o desemprego e a informalidade, promovendo a inclusão social. $\mathrm{O}$ esteio da proposta foi uma estratégia de valorização real do salário (entre 2003 e 2013, o valor real do salário mínimos cresceu 72\%), associada ao acesso ao crédito pessoal e aos programas de transferência de renda - o Programa Bolsa Família. Mais recentemente, foi judicializada outra forma de inserção no mercado de trabalho, como é o caso do Microempreendedor Individual (MEI), que absorveria grande parte dos trabalhadores autônomos ou independentes. ${ }^{2}$ Essas ações favoreceram a arrecadação tributária e as contribuições previdenciárias que por sua vez estimularam os gastos públicos.

Do ponto de vista social, os avanços foram enormes. Dos anos 2003 a 2012, por exemplo, o índice de Gini reduziu-se 17,8\% (1,8\% ao ano, em média), enquanto a taxa de pobreza diminuiu $61,8 \%$ (5,5\% ao ano, em média) (Pochmann, 2014). A miséria foi extinta e o Programa Bolsa Família, que atinge 13,8 milhões de famílias, exige a permanência das crianças pobres na escola e o acompanhamento das condições de saúde. Esse modelo intitulado por alguns de "crescimento baseado no consumo" esteve também ancorado em gastos de investimentos em infraestrutura (estradas, ferrovias, hidroelétricas) e nos setores de petróleo e gás.

As relações internacionais também foram revistas. Ampliou-se a parceria com alguns países da América Latina e da África, bem como reduziu-se a dependência brasileira em relação aos Estados Unidos, substituído pela China como parceiro comercial prioritário. Havia também em curso uma proposta de inserção na geopolítica mundial com mais autonomia.

Com a crise de 2008, o Brasil foi exitoso no manejo de políticas anticíclicas implementadas pelos bancos públicos e o país passou quase incólume pelo auge da crise (os bancos públicos possuem hoje $55 \%$ do mercado contra 35\%, em 2009). Tal como nos países desenvolvidos, as medidas contracíclicas implementadas estiveram centradas em desonerações fiscais, manutenção/ampliação dos gastos do governo, ampliação dos recursos voltados para o seguro-desemprego, medidas especiais para setores estratégicos em dificuldades, como é o caso da automotiva.

Do ponto de vista concreto, a implementação desse projeto se consubstanciou na mudança da composição populacional em shoppings centers, aero- 
portos, supermercados universidades e agências de viagem. Os pobres passaram a ser vistos em ambientes nunca antes visitados... Tornou-se muito difícil, para alguns segmentos de classe, aceitar a participação tão ostensiva das chamadas classes $\mathrm{C}$ e $\mathrm{D}$ em ambientes antes frequentados, majoritariamente, pelas classes $\mathrm{A}$ e B.

\section{Os governos de Dilma Rousseff}

No seu primeiro governo, Dilma foi ousada, buscando reduzir os riscos presentes na economia brasileira, bem como os sinais que aproximavam o governo do neoliberalismo, como a presença de Henrique Meirelles, no Banco Central. Dilma não fez nenhuma carta aos brasileiros e, portanto, parecia mais livre para agir.

Escolheu um servidor de carreira para o Banco Central e implementou um programa de redução da taxa de juros inédito no país, inaugurando uma fase na qual tivemos a mais baixa taxa de juros real do período recente. Desacreditou na parceria inflação baixa-juro alto e inaugurou uma política heterodoxa, com pressões para redução do spread bancário sabidamente abusivo, através da atuação dos bancos públicos. A Selic chegou a 7,25 em dezembro de 2012. Por isso, entretanto, ela sofreu enormes críticas da imprensa, que se fez porta-voz do mercado financeiro. As críticas eram diárias, insistentes, e ela recuou.

Por outro lado, o governo Dilma desde 2011 sofre as consequências da mudança do cenário internacional, marcado pela redução do crescimento dos países emergentes, notadamente China e Índia, a crise do euro e a frágil recuperação americana. Adicionalmente, o consumo das famílias também desacelera nesse ano. A continuidade das ações anticíclicas revela que houve uma subestimação dos seus efeitos sobre o quadro fiscal brasileiro, bem como sobre as contas externas brasileiras.

Também contribuiu para o atual quadro de desgaste e descrença a intervenção no setor elétrico. Apesar de acertada a medida de intervir no mercado de energia para renegociar os contratos, uma vez que os investimentos já haviam sido amortizados, os efeitos danosos da seca geraram pressões sobre os preços da energia, impulsionando a inflação.

É importante destacar uma certa inflexão que ocorreu no modelo até então adotado. O governo Dilma tenta aumentar o estímulo ao investimento privado que já vinha sendo estimulado pelas ações do BNDES. A tentativa foi de conferir maior consistência à política econômica através do aumento dos investimentos privados, tornando o setor produtivo mais parceiro das mudanças em curso. Nesse contexto, as desonerações ajudariam a manter os empregos e aumentariam os investimentos.

Certamente, o governo Dilma apostou excessivamente nas desonerações da folha de pagamentos (folha de salários) que retirou a cota patronal da previdência $(20 \%)$ referente à remuneração do trabalho. Essa cota foi substituída por uma contribuição sobre a receita bruta, de $2,5 \%$ e $1,5 \%$, dependendo do setor 
ou produto, alíquotas essas que foram posteriormente reduzidas para $2,0 \% \mathrm{e}$ 1,0\%. Os objetivos explícitos eram ampliar a geração de empregos ou evitar o desemprego e, ainda, melhorar a competitividade das empresas estimulando-as a investir mais. Essa expectativa não se cumpriu e é provável que essa medida tenha simplesmente ampliado a margem de lucros das empresas.

O governo esperava que a redução do custo do trabalho estimulasse a criação de emprego, quando é sabido que a demanda por trabalhadores depende do comportamento do mercado de bens, o que por sua vez depende da expectativa de lucratividade do empresário, ambas em queda.

Ademais, havia também a expectativa de melhora da competitividade que viria pela redução dos custos de produção associados à diminuição dos encargos incidentes sobre a folha de salários, sem afetar a remuneração dos empregados ou seus direitos previdenciários. $\mathrm{O}$ desempenho das exportações e a redução de custos estimulariam a geração de empregos formais e ampliariam a formalização do mercado de trabalho.

É provável que se esses recursos houvessem sido gastos diretamente pelo governo em habitação popular ou infraestrutura em geral o ganho houvesse sido positivo e concreto.

Pinto (2015), com metodologia própria, evidencia que mesmo no período Dilma, o desempenho da rentabilidade sobre o patrimônio líquido das empresas mantém-se em níveis altos para o setor financeiro, reduz-se para a indústria de transformação mas ainda permanece em patamares altos, em torno dos 10\%. Ou seja, em estruturas de mercado oligopólicas com presença de empresas multinacionais e sem cobrança explícita de contrapartida fica difícil induzir o setor privado a usar os recurso na direção esperada.

É possível dizer que houve um erro na gestão do governo Dilma? Acho que esse fato ilustra muito bem o conflito que há entre a urgência colocada pelo curto prazo e uma análise de médio/longo prazo. Tudo indica que o governo Dilma decidiu olhar pouco para as mudanças no cenário mundial que já vinha recuando desde 2010 e acreditar nos mecanismos já em curso, como as desonerações, para manter a política anticíclica inaugurada pelo governo Lula.

A conjugação do real apreciado e juros estratosféricos, na ausência de uma política industrial que reverta a vulnerabilidade externa, retrata-se na reprimarização da pauta exportadora brasileira; em 2000, a participação dos produtos manufaturados era de $60 \%$ e, em 2013, essa participação cai para 39,3\%. A mudança também ocorre na pauta importadora e a importação de bens de consumo duráveis cresce 8,9 vezes entre 2002 e 2013 (Cano, 2014, p.165 e 169). Como não poderia deixar de ser, a combinação juros-câmbio pressiona também, e de forma significativa, as transações correntes do nosso balanço de pagamentos. 
Gráfico 1 - Brasil. Rentabilidade sobre o patrimônio líquido (\%)

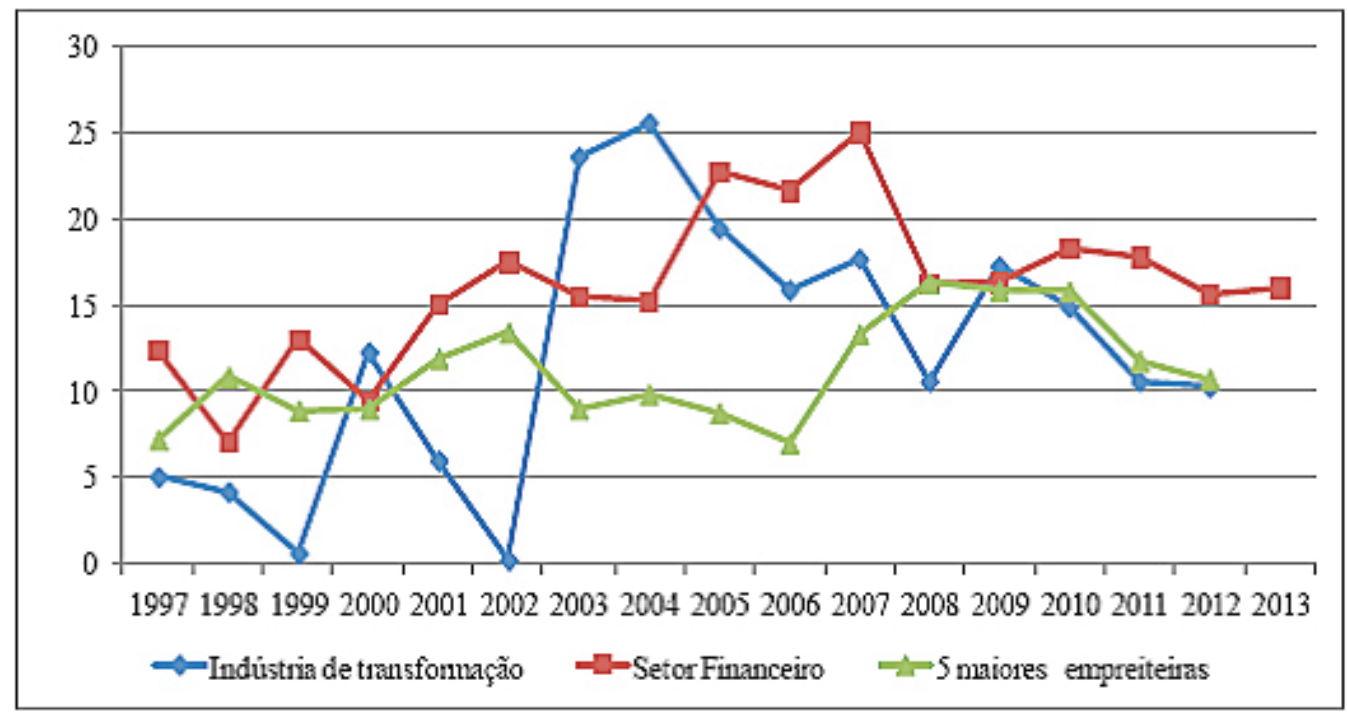

Fonte: Base de dados própria, a partir das informações da revista Exame (Maiores e Melhores) para a indústria de transformação (com exceção dos sub-ramos petróleo e gás, refino de petróleo e coque e álcool) e para as empreiteiras; e das revistas Balanço Anual da Gazeta Mercantil (para o setor financeiro entre 1997 e 2004) e Valor grupos econômicos (para o setor financeiro entre 2005 e 2012).

\section{Os governos do PT e mercado de trabalho}

O Brasil não mede o desemprego para o país como um todo e, em geral, utilizam-se as taxas produzidas para as seis principais regiões metropolitanas do país. ${ }^{3}$ Esse é talvez o indicador mais revelador do sucesso dos últimos onze anos. A taxa de desemprego caiu de $12,4 \%$ da PEA, em 2003, para 4,8\% em 2014, segundo a PME/IBGE.

Já a formalização do mercado de trabalho, segundo Rais/Caged/MTE é grandiosa, pois entre 2003 e 2014 foram criados 21,2 milhões de novos postos de trabalho. Não há o que discutir: foi uma revolução no mercado de trabalho. Um outro dado positivo para os trabalhadores foi o ganho real obtido nas negociações salariais. Do total dos reajustes examinados, em 2014, pelo Dieese, 92\% apresentaram aumento real, enquanto $6 \%$ igualaram-se ao índice inflacionário e $2 \%$ não obtiveram ganhos reais (Dieese, 2015b).

Mas o subdesenvolvimento impõe a sua marca no mercado de trabalho, desmistificando um pouco a natureza da revolução vivida. O setor de atividade que mais emprega é a construção civil, seguida pelo comércio e extrativa mineral; a indústria de transformação tem uma participação bem menor. Do mesmo modo, as ocupações criadas são de baixo salário, reforçando o "mantra" de que a estrutura salarial é dominada por trabalhadores que ganham até dois salários mínimos, o que é compatível com o crescimento do salário médio no período (Saboia, 2014). 


\section{O ajuste neoliberal do segundo governo Dilma Rousseff}

Tudo indica que a tentativa de continuar com as políticas anticíclicas num contexto de queda das demandas externa e interna e de ausência de respostas dos investimentos privados "selou" essa necessidade. O estopim certamente foi a evidência de um resultado negativo nas contas públicas de R $\$ 32,5$ bilhões, o que corresponde a $0,6 \%$ do PIB, que foi magnificado pela mídia, apresentado como o resultado do descontrole das contas públicas, das "pedaladas" fiscais da Dilma, dando munição para o ambiente de descontentamento, confrontos e até mesmo "ódio" contra o PT no país.

O segundo governo Dilma decide implementar um corte nos gastos de 70 bilhões de reais, anunciando que essa seria a "senha" para a retomada do crescimento num futuro próximo em condições mais sólidas, ou seja, mais confiáveis do ponto de vista do mercado. Fica difícil sustentar o argumento de que associar juros altos e corte nos gastos governamentais leve à retomada do crescimento. $\mathrm{O}$ que tende a ocorrer é queda do crescimento econômico, desestímulo aos investimentos com todas as consequências negativas sobre o emprego e a renda. Esse corte já atinge o PAC, os gastos com saúde e, sobretudo, a educação superior com suspensão de bolsas de pós-graduação em diferentes áreas disciplinares, atraso na transferência de verbas para as universidades, atraso no desembolso dos recursos do Fies, do Pronatec e a suspeita da suspensão dos programas Ciência sem Fronteira e Farmácia Popular. Falta pouco para o corte atingir o Programa Bolsa Família.

Foram também alteradas as regras de alguns programas sociais como o seguro-desemprego e o abono salarial. Para acessar o seguro-desemprego o trabalhador terá de ter trabalhado durante 18 meses na primeira solicitação. $\mathrm{O}$ trabalhador agora só terá direito ao abono salarial se trabalhar durante seis meses corridos. Também foram alteradas as condições de acesso a pensão por morte a qual, há muito tempo, já vinha sendo apontada como uma "jabuticaba" brasileira diante das frágeis exigências de acesso quando comparadas com outros países.

A política de desoneração da folha de pagamentos está sendo revista e as contribuições patronais foram alteradas de $1 \%$ e $2 \%$ para $2,5 \%$ e $4,5 \%$ sobre a renda bruta declarada. Há um conjunto de modificações nos impostos na busca do aumento da arrecadação, a volta da alíquota cheia para o IPI que incide sobre automóveis, elevação da contribuição do PIS/Confins sobre produtos importados, o IPI sobre cosméticos e a correção da tabela do imposto de renda. O impacto dessas mudanças sobre os preços e a inflação ainda é uma incógnita.

Os impactos do ajuste, no entanto, já são visíveis no mercado de trabalho. Nos últimos doze meses (agosto 2014-agosto 2015) o mercado de trabalho brasileiro perdeu 985.669 postos de trabalho formais, segundo o Caged-MTE.

A última divulgação do IBGE, em setembro de 2015, revela que entre agosto de 2014 e agosto de 2015 a taxa de desemprego passa de $5,0 \%$ para $7,6 \%$, nas seis regiões metropolitanas estudadas. 
A ampliação do desemprego vai gerar importantes alterações nas formas de inserção dos desempregados na busca pela sobrevivência: aumentará a busca pela condição de trabalhador autônomo e aumentará a informalidade. Desemprego, informalidade e desproteção social estão de volta ao cenário brasileiro. Os efeitos sobre os rendimentos também já são visíveis. O rendimento real de agosto foi $0,5 \%$ maior do que o de julho, e $3,5 \%$ menor do que o de agosto de 2014 , segundo o IBGE. Na avaliação do Dieese (2015a), durante o primeiro semestre deste ano, aproximadamente $69 \%$ das negociações analisadas conquistaram aumentos reais, percentual bem menor do que o encontrado em 2014.

O tamanho do ajuste aplicado na economia brasileira ao impactar sobre o mercado de trabalho reduz um dos elementos centrais do crescimento do período 2006-2013: a demanda interna. Do mesmo modo, a ampliação do desemprego, por sua vez, reduz a arrecadação de impostos, reduz o consumo, gerando uma reação negativa em cadeia que atingirá negativamente os investimentos.

Concretamente, o cenário internacional não dá sinais positivos de que será possível, num curto espaço de tempo, um significativo aumento do comércio mundial que volte a favorecer o crescimento no Brasil. A perspectiva do crescimento chinês é de $3 \%$ a $4 \%$ e não mais de taxas de $7 \%$ a $8 \%$ como no passado recente.

Considerando a massa de desempregados já produzida e o efeito cruzado das diferentes alterações implementadas, injetou-se na sociedade brasileira forte dose de desânimo e descrença no futuro. De forma ainda mais incisiva desarma-se um modelo de inclusão que valorizava o mercado interno e a formalização do mercado de trabalho. ${ }^{4}$

\section{Política econômica, mercado de trabalho e democracia}

Muito mais do que uma disputa entre orientações de política econômica e escolas de pensamento econômico, o que está em jogo na sociedade brasileira é o seu futuro e a possibilidade de construção da nação brasileira. O Brasil vem, nos últimos trinta anos, buscando fortalecer a sua democracia e os impactos do ajuste promovido pelo segundo governo Dilma são visíveis e apontam na direção de um retrocesso social significativo.

A conjugação entre condições restritivas externas e aumentos dos gastos governamentais, no primeiro governo Dilma, revela que a consolidação da democracia entre nós exige a busca de soluções alternativas que não reproduzam permanentemente o círculo vicioso que se inicia com as pressões das contas externas, passam pelas exigências de produção de superávit primário que alimentam permanentemente os rentistas externos e internos (alavancados por uma taxa inexplicavelmente estratosférica) e terminam por subjugar a grande maioria da população brasileira.

Mais grave do que a crise econômica que atravessamos é o seu uso para embaçar a direção que se precisa tomar. A agressividade da campanha política de 2014 associada à insatisfação dos brasileiros, que se sentiram prejudicados pelo 
movimento inclusivo construído nos últimos doze anos, desqualificam o êxito da "era PT" em contribuir para a construção de um país melhor.

É inegável que temos um conflito no qual a resistência em enxergar que o país mudou e que os incluídos nos últimos doze anos não recuarão de suas posições facilmente, em nada contribui para uma solução. Ao mesmo tempo a crise da democracia representativa, que é mundial, e que entre nós se revela no Congresso mais conservador dos últimos tempos, reforça o entendimento de que as alternativas para o encaminhamento dessa crise precisam ser negociadas.

Ao invés de apontar um governo incompetente e irresponsável é necessário reconhecer que o déficit que originou o ajuste responde aos reclamos da democracia, da qual muitos de nós não quer e não vai abrir mão. Nesse sentido, o mercado de trabalho tem um papel fundamental e precisa ser preservado.

\section{Observações finais}

Ao longo deste artigo buscou-se evidenciar que a política econômica brasileira, na grande maioria das vezes, é prisioneira da macroeconomia de curto prazo e tem evitado enfrentar a superação de seus condicionantes histórico-estruturais. Aqui mencionamos apenas um aspecto que nos parece central: a questão industrial. O Brasil vem construindo desde os anos 1980 um processo de desindustrialização (Carleial, 2004; Cano, 2014) subestimado, muitas vezes, pela hipótese de que entramos na era da terciarização como os países desenvolvidos, o que explicaria a dominação do setor terciário na absorção da força de trabalho. Essa hipótese não se sustenta, uma vez que a perda de participação do valor agregado industrial no valor agregado total ocorreu quando a renda per capita média brasileira ainda era muito baixa (Carleial; Ferreira, 2013).

Recuperar a indústria brasileira precisa ser um objetivo a ser perseguido. O processo de desvalorização do real na perspectiva de um ajuste externo da economia brasileira já trabalha nessa direção, porém é insuficiente.

O governo Dilma concebeu uma proposta de política industrial que, a nosso ver, melhor se aproximou das necessidades brasileiras. O Plano Brasil Maior reconheceu a necessidade de adensamento das cadeias produtivas ( $\grave{a}$ la Hirschman) esvaziadas pela política de abertura comercial indiscriminada, porém também não obteve os resultados esperados. Por que fracassou essa política? O Plano Brasil Maior e a Política Nacional de conteúdo local poderiam ser assumidos pelas federações de indústrias do país, com o apoio do BNDES, e poderiam promover um salto na estrutura produtiva brasileira.

Considerando o movimento de redução das importações que ocorre em razão da desvalorização do real, abrem-se possibilidades de produzir internamente o que antes era importado? Que instância está monitorando tais alternativas/possibilidades? Que instância melhor conhece as realidades regionais? $\mathrm{O}$ fortalecimento da indústria certamente significará também um anteparo para as pressões externas, reduzindo a nossa vulnerabilidade, e ainda fortalecerá o 
mercado de trabalho que poderá gerar postos de trabalho de melhor qualidade e melhor remunerados.

Essa é uma alternativa que não exclui outras, como a quebra do paradigma de que o controle dos preços só se fará com juros estratosféricos mesmo na ausência de pressões de demanda.

Finalmente, retomando um aspecto abordado no item anterior, a saída dessa crise exige que se fale mais dela. É preciso que essa discussão ganhe novos espaços: universidades, sindicatos, $\mathrm{ONG}$, associações da sociedade civil, praças; enfim, a saída precisa ser consensual, negociada. Os brasileiros precisam escolher a direção que querem tomar. Só a construção de um projeto nacional de desenvolvimento poderá nos levar em direção a uma sólida democracia que permita a emergência dos valores republicanos. Utopia? Pode ser, mas precisamos mesmo delas para viver. Como diria Galeano: “elas nos fazem caminhar”!

\section{Notas}

l Esse argumento está presente em Marini (2000) e Furtado (2000), entre outros.

2 Trabalhador autônomo e/ou independente são os trabalhadores por conta própria que não se enquadram na condição de trabalhador subordinado como definido pelo direito do trabalho.

3 São seis as regiões metropolitanas analisadas pela PME-IBGE: São Paulo, Rio de Janeiro, Belo Horizonte, Porto Alegre, Salvador e Recife.

4 Em julho passado, o governo Dilma, lançou um programa de proteção ao emprego que permite a redução da jornada de trabalho em até $30 \%$ com redução também de salário. Até o momento não há avaliações sobre adesões a esse programa.

\section{Referências}

AREND, M.; FONSECA, P. D. 1 (1955-2005): 25 anos de catching up, 25 anos de falling behind. Revista de Economia Politica, v.32, n.1, p.33-54, jan./mar. 2012.

CANO, W. (Des)industrialização e (Sub)desenvolvimento. Cadernos de Desenvolvimento, CICEF, Rio de Janeiro, v.9, n.15, p.139-175, 2014.

CARLEIAL, L. Subdesenvolvimento globalizado: a resultante das escolhas de política econômica nos anos noventa. Revista do Ipardes, Curitiba, n.106, p.11-35, 2004.

CARLEIAL, L.; FERREIRA, C. Estrutura produtiva e tecnologia: as possibilidades de um país subdesenvolvido no século XXI. San Francisco: NYC, Lasa. 2013.

CERQUeIRA LEITE, R. C. De quem é a culpa?. Folba de S.Panlo, São Paulo, 4 set. 2015 .

CHESNAIS, F. A finança mundializada: raízes sociais e políticas, configuração, consequências. São Paulo: Boitempo, 2005. 
DIEESE. Balanço das negociações dos reajustes salariais do primeiro semestre 2015. Série Estudos e Pesquisas, São Paulo, n.77, ago. 2015a.

Balanço das negociações dos reajustes salariais em 2014. Série Estudos e Pesquisas, São Paulo, n.75, mar. 2015b.

FURTADO, C. Desenvolvimento e subdesenvolvimento. In: BIELSCHOWSKY, R. Cinquenta anos de pensamento da CEPAL. Rio de Janeiro: Record, 2000. v.1, p.239.

MARINI, R. M. A dialética da dependência: uma antologia da obra de Ruy Mauro Marini. Rio de Janeiro: Vozes; Buenos Aires: Clacso, 2000.

PEREZ, C. Finance and technical change: a long-term view. In: HANUCH, H.; PYKA, A. (eds). The elgar companion to neoschumpeterian economics. Cheltenham Edward: Elgar, 2004.

PIKETTY, T. O capital no século XXI. Rio de Janeiro: Intrinseca, 2014.

PINTO, E. C. Dilma: de "coração valente" a presidente acuada. Texto para Discussão n.15. Rio de Janeiro: IE/UFRJ, set. 2015.

POCHMANN, M. Brasil: segunda grande transformação no trabalho? Estudos Avançados, São Paulo, v.28, n.8, p.23-38, maio/ago. 2014.

SABOIA, J. Baixo crescimento econômico e melhora no mercado de trabalho. Como entender a aparente contradição. Estudos Avançados, v.28, n.81, p.115-125, maio/ago. 2014.

SAMUELSON, P. A.; NORDHAUS, W. D. Economics. 18.ed. Boston; New York: McGraw-Hill, 2005.

RESUMO - O principal objetivo deste artigo é discutir os efeitos do ajuste fiscal implementado pelo segundo governo Dilma Rousseff, especialmente sobre o mercado de trabalho brasileiro. Esse ajuste já gerou resultados negativos, provocando a perda de postos de trabalho formais, ampliando o desemprego e reduzindo as possibilidades de manutenção dos ganhos reais obtidos pelos trabalhadores brasileiros nos últimos dez anos. Essa crise também é reveladora da permanência da vulnerabilidade externa brasileira e da importância dos nossos condicionantes histórico-estruturais na definição de cada conjuntura econômica. A mitigação dos efeitos desse ajuste exigirá uma forte negociação política em torno de um projeto nacional de desenvolvimento.

Palavras-CHAVE: Mercado de trabalho, Política econômica, Democracia.

ABSTRACT - The main objective of this article is to discuss the effects of the tax adjustments implemented by the second government of President Dilma Rousseff, especially regarding the Brazilian labor market. This adjustment has already produced negative results, leading to the loss of formal jobs, spreading unemployment and reducing the chances of maintaining real gains won by Brazilian workers in the last ten years. This crisis has also revealed the permanent state of Brazilian external vulnerability and the 
importance of our historical and cultural conditioning in the definition of each economic circumstance. The mitigation of the effects of this adjustment will require the strong political negotiation of a national development project.

KEYWORDS: Labor market, Economic policy, Democracy.

Liana Maria da Frota Carleial é economista, doutora em Teoria Econômica pela Universidade de São Paulo com estágio de Pós-doutorado na Université Paris XIII, no Centre de Recherche em Économie Industrielle. Professora titular da Universidade Federal do Paraná. Professora convidada da Faculdade de Direito da mesma Universidade. Atualmente, é presidente do Instituto Municipal de Administração Pública - IMAP da municipalidade de Curitiba. @ - liana.carleial@gmail.com

${ }^{\text {I } U n i v e r s i d a d e ~ F e d e r a l ~ d o ~ P a r a n a ́, ~ C u r i t i b a / P a r a n a ́, ~ B r a s i l . ~}$

Recebido em 29.9.2015 e aceito em 16.10.2015. 